\title{
The closed-loop pathways of signaling molecules
}

\author{
Authors: Yang LIU*
}

\begin{abstract}
Affiliations:
The Hong Kong Polytechnic University, Hung Hom, Kowloon, Hong Kong.

*To whom correspondence should be addressed: mmyliu@ polyu.edu.hk
\end{abstract}

The pathways of signaling molecules are important to understanding how signaling molecules regulate physiological function and also in predicting the pathological development which is important to therapeutic strategy, however the thorough knowledge of these pathways is still lack. In this paper, we used the big data concept to analyze the pathways of signaling molecules and categorize these molecules into five groups according to their origin and effect on the five organs of heart-spleen-lung-kidney-liver. Heart group includes IGF, Ang and Mg; spleen group includes ANP, aldosterone, retinoic acid and ghrelin; lung group includes FGF7, VEGF, ascorbic acid and HIF; kidney group includes calcitonin, PTHrP, Wnt and NO; and liver group includes EPO, renin, SOD, AKR and GSH. We found that each group of molecules have assisting effect on the other organ in the order of heart-spleen-lung-kidney-liver-heart, and have regulating effect on the other organ in the order of heart-lung-liver-spleen-kidney-heart. Moreover, the pathways of molecules of each group also follow these two arrangements, in which the pathways of molecules form a closed-loop that may lead to new therapeutic strategies.

Key words: Signaling molecules, pathways, closed-loop, therapeutic strategy. 


\section{Introduction}

The pathways of signaling molecules are important to understanding how signaling molecules regulate physiological function and also in predicting the pathological development which is important to therapeutic strategy. However, despite the documented importance of signaling molecules to human life, we still lack thorough knowledge of pathways of signaling molecules. It is well known that heart, spleen, lung, kidney and liver generate/secret important signaling molecules which have significant effect on human physiological processes through signaling pathways. Where liver generates insulin-line growth factor (IGF), heart produces atrial natriuretic peptide (ANP), spleen generates fibroblast growth factor-7 (FGF7) and vascular endothelial growth factor (VEGF), lung secrets calcitonin and parathyroid hormone-related protein (PTHrP), and kidney produces erythropoietin (EPO). These are key signaling molecules, and there are other molecules that regulate or inhibit these key signaling molecules. Here we used Big Data concept to analyze the pathways of these signaling molecules, and categorize these signaling molecules into five groups according to their origin and effect on a particular organ. We named these group as heart group, spleen group, lung group, kidney group and liver group. Heart group includes IGF, Angiotensin (Ang), and Magnesium (Mg); spleen group includes ANP, aldosterone, retinoic acid and ghrelin; lung group includes FGF7, VEGF, ascorbic acid, and hypoxia inducible factor (HIF); kidney group includes calcitonin, PTHrP, Wnt, nitric oxide (NO); and liver group includes EPO, superoxide dismutase (SOD), renin, aldo-keto reductase (AKR), and glutathione (GSH). As shown in Figure 1, within each group, the signaling molecules regulate each other and form a small closed-loop of pathways. Among those five groups, each group have assisting effect on other organ in the order of heart-spleen-lung-kidney-liverheart, and have regulating effect on the other organ in the order of heart-lung-liver-spleenkidney-heart. Moreover, the molecules of each group regulate those in other group also in the 
orders of heart-spleen-lung-kidney-liver-heart and heart-lung-liver-spleen-kidney-heart.

Therefore, we may constitute the closed-loop pathways of these signaling molecules.

\section{Method}

We apply the following selection method to identify the signaling molecules.

\section{Step 1: identify the key molecules}

It is known that heart generates ANP, spleen produces FGF7 and VEGF, lung secrets calcitonin and PTHrP, kidney generates EPO, and liver generates IGF respectively. Since IGF has significant effect on heart, ANP has significant effect on spleen, FGF7 and VEGF have significant effect on lung, calcitonin and PTHrP have significant effect on kidney, and EPO has significant effect on liver, we set IGF as key molecule of "heart group", ANP as key molecule of "spleen group", FGF7 and VEGF as key molecules of "lung group", calcitonin and PTHrP as key molecules of "kidney group", and EPO as key molecule of "liver group". In Figure 1, along the outer circle of heart-spleen-lung-kidney-liver-heart, the key molecule of each group is generated by the previous organ.

$\underline{\text { Step 2: identify the signaling molecules in each group }}$

These key signaling molecules usually have proliferating or warming effect. There should exist other signaling molecules that have shrinkage or cooling effect and also have significant effect on the same organ, i.e., within the same group, the molecules should have contrary effect or regulate each other, thus the functions of these signaling molecules should be

$\phi_{1}$ : proliferation or warming, (for key signaling molecule),

$\phi_{2}:$ shrinkage or cooling,

$\phi_{3}:$ activation or regulation.

Suppose the signaling molecules form the following set, 
$\mathrm{X}=\{\mathrm{x}$ : signaling molecules $\}$.

Then, we find the signaling molecules for each group as following set:

Heart group $=\left\{x: \phi_{1}, \phi_{2}, \phi_{3}\right\}$,

Spleen group $=\left\{x: \phi_{1}, \phi_{2}, \phi_{3}\right\}$,

Lung group $=\left\{x: \phi_{1}, \phi_{2}, \phi_{3}\right\}$,

Kidney group $=\left\{x: \phi_{1}, \phi_{2}, \phi_{3}\right\}$,

Liver group $=\left\{x: \phi_{1}, \phi_{2}, \phi_{3}\right\}$.

Within each group, the molecules form a closed-loop regulating relationship.

Step 3: Determining the intrinsic relationships among molecules of these five groups

By comparison and iteration, we determine the interrelationships each group of molecules with organs, and the pathways of molecules among these five groups. Thus, we could establish a "large" closed-loop pathways among the molecules of these five groups.

\section{Results}

\subsection{The signaling molecules in each group and their regulating relationship}

The molecules in each group are tabulated in Table 1.

\subsubsection{Heart group consists of IGF, Ang and Mg}

IGF is secreted by liver and is important to heart function. IGF-1 signaling regulates metabolism, contractility, senescence, autophagy, hypertrophy, and apoptosis in the heart; it activates canonical and noncanonical signaling pathways in the heart; deficiency in IGF-1 may drive cardiovascular disease, and local IGF-1 therapy can prevent heart injuries in experimental models [1]. IGF-1 has warming effect [2].

Ang is secreted by liver; Ang II regulates cardiac and blood vessel contractility, and is involved in cardiac growth, remodeling, and apoptosis [3]. Ang II induces hypothermia [4], which is contrary to IGF. 
$\mathrm{Mg}$ is important to normal heart rhythm and is a cofactor in more than 300 enzyme systems that regulate diverse biochemical reactions in the body, including blood pressure regulation and blood glucose control [5].

IGF, Ang and Mg regulate each other and form the small closed-loop pathways, as shown in the heart group of Figure 1. It was found that Ang II infusion in rat decreases levels of circulating and skeletal muscle IGF-1 [6], Ang II stimulates cardiac IGF-1 [7] and transcription of IGF-1 receptor in vascular smooth muscle cells [8], and IGF-1 reduces Ang II [9]. Moreover, the exposure of the platelets to Ang II significantly decreases intracellular Mg concentrations [10], and Mg levels are strongly associated with IGF-1 [11].

\subsubsection{Spleen group consists of ANP, aldosterone, retinoic acid, and ghrelin}

ANP is secreted by heart muscle cells that intervenes in the short- and long-term control of blood pressure and of water and electrolyte balance [12]. The spleen is an important site of ANP-induced fluid extravasation into the systemic lymphatic system. ANP enhances the extravasation of isoncotic fluid from the splenic vasculature both by raising intrasplenic microvascular pressure and by increasing filtration area [13]. Moreover, maintaining body temperature is an important function of ANP [14].

Aldosterone retains needed salt in human body and helps control blood pressure, the balance of electrolytes in blood, and the distribution of fluids in the body. An intracardiac production of aldosterone was recently found in rat [15]. Aldosterone increases spleen size and weight [16]. Retinoic acid (vitamin A) controls the homeostasis of splenic cells [17] and is generated by the epicardium [18]. Moreover, either aldosterone or retinoic acid inhibits heat generation in body [19] [20], which are contrary to ANP. 
Ghrelin is a gastric peptide that regulates the distribution and consumption of energy. Ghrelin inhibits proliferation of splenic T cells [21] and effectively regulates food intake and energy homeostasis [22].

The spleen group in Figure 1 shows the contrary effect and supportive relationship between ANP and aldosterone/retinoic acid. ANP has exactly opposite function of aldosterone, ANP decreases circulating aldosterone and vice versa [23]. Retinoic acid signaling markedly stimulates natriuretic peptide receptor-A gene expression [24]. Moreover, it was found that ANP level decreases significantly after treatment with ghrelin in a rat model [25]; ghrelin elevates aldosterone [26]; and applying ghrelin supplementation to normal lungs increased retinoic acid receptor $\alpha / \gamma$ expression [27].

\subsubsection{Lung group consists of FGF7, VEGF, ascorbic acid and HIF}

FGF7 is secreted by spleen [28] and is a potent mitogen that enhances cell proliferation in various organs, including the lung, skin, intestine, breast, and liver. It controls the lung morphogenesis, respiratory epithelial cell differentiation and proliferation [29].

VEGF is critical for the development and maintenance of the lung and also plays a role in several acute and chronic lung diseases [30]. It was found that splenic T cells produce VEGF [31]. VEGF is important for brown adipose tissue development and maintenance in which the function of brown adipose tissue is to generate body heat [32].

Ascorbic acid (Vitamin C) was identified in the early 1900s in the search for a deficient substance responsible for scurvy which was directly linked to pneumonia. Vitamin $\mathrm{C}$ is a physiological antioxidant protecting host cells against oxidative stress caused by infections, and plays a role on preventing and treating pneumonia [33] and other lung disease [34]. It was found that vitamin $\mathrm{C}$ content in spleen is much higher than that in other organs 
[35] and there exists an extracellular pool of ascorbic acid in lung maintained even during scurvy [36].

HIF which is a highly conserved transcription factor that is present in almost all cell types, is tightly regulated by oxygen availability, and regulates the expression of hundreds of genes. HIF system plays a critical role in pulmonary development [37].

The lung group in Figure 1 shows the contrary and regulating interrelationship of HIF, FGF7, VEGF and vitamin C. HIF-1 activates VEGF transcription in hypoxic cells [38]. HIF promotes the expression of FGF7 mRNA levels [39]. Vitamin C prevents endothelial VEGF and VEGFR-2 overexpression [40] and inhibits NO-induced HIF-1 $\alpha$ stabilization and accumulation [41].

\subsubsection{Kidney group consists of Calcitonin, PTHrP, Wnt and NO}

Both calcitonin and PTHrP are secreted from lung [42] [43]. Calcitonin augments the renal reabsorptive capacity for calcium [44], PTHrP is potent renal regulating factor and mitogenic for various renal cell types, and plays a role in renal development [45]. Both calcitonin and PTHrP have "warming" effect [46, 47].

Wnt signaling regulates cell-to-cell interactions during development and adult tissue homeostasis, and is associated with kidney development and kidney diseases [48]. Several Wnt genes are expressed in lung [49]. Wnt signaling blocks thermogenesis [50] which is contrary to calcitonin and PTHrP.

$\mathrm{NO}$ is the second messenger and a major regulator in the cardiovascular, immune, and nervous systems. In the kidney NO has numerous important functions including the regulation of renal hemodynamics, maintenance of medullary perfusion, mediation of pressure-natriuresis, blunting of tubuloglomerular feedback, inhibition of tubular sodium reabsorption, and modulation of renal sympathetic neural activity [51]. 
The spleen group in Figure 1 shows the interrelationships among calcitonin, PTHrP, Wnt and NO. Calcitonin stimulates expression of sclerostin [52] which is an inhibitor of Wnt, and administration of PTHrP can increase Wnt signaling [53]. Moreover, calcitonin increases plasma NO levels [54], PTHrP activates NO release [55], and Wnt-5a increases NO production [56].

\subsubsection{Liver group consists of EPO, renin, SOD, AKR, and GSH}

EPO is produced principally in the liver during fetal gestation and mainly in the kidney for adult [57]. EPO is a glycoprotein that promotes the proliferation and differentiation of erythrocyte precursors. It was reported that high-dose EPO increases liver regeneration by affecting the biochemical, morphological, and histopathological parameters after liver resection [58]. EPO increases brown fat gene expression [59].

Renin is produced in kidney and exerts significant effect on liver. The renin-substrate concentration in patients with liver disease is much lower than that of normal subjects [60]. Blockade of the renin-angiotensin system improves liver regeneration [61], i.e., renin is not favor liver proliferation.

SOD is an important antioxidant defense in nearly all living cells exposed to oxygen and is intensively expressed in kidney [62]. SOD mimetic improves the function, growth and survival of small size liver grafts after transplantation in rats [63] and $\mathrm{Cu} / \mathrm{Zn}$ SOD is broadly distributed in liver [64]. It was found that cold-exposure activates brown adipose tissue thermogenesis but decreases SOD expression [65], indicating SOD has "cooling” effect.

AKR is expressed in kidney [66]. The AKR superfamily comprises of several enzymes that catalyze redox transformations involved in intermediary metabolism, detoxification and biosynthesis [67]. AKR-7A protects liver cells and tissues from 
acetaminophen-induced oxidative stress and hepatotoxicity [68]. Cold-exposure suppresses AKR level significantly [69], indicating AKR has “cooling” effect.

GSH is a substance produced naturally by the liver and effectively scavenges free radicals and other reactive oxygen species [70]. GSH plays a key role in the liver in detoxification reactions.

The liver group in Figure 1 shows the interrelationships among EPO, renin, SOD, AKR and GSH. When treated with EPO, the GSH and SOD levels in kidney of rats are significantly decreased [71]. The extracellular SOD is a major repressor of hypoxia-induced EPO gene expression [72], but treatment with EPO increases vascular expression of SOD1 [73]. SOD and GSH work together to prevent or repair the damage caused by reactive oxygen species. SODs convert superoxide radical into hydrogen peroxide and molecular oxygen, while the GSH peroxidases (GPx) convert hydrogen peroxide into water, and GSH helps the productivity of GPx [74]. GSH and AKR are also interrelated, since GSH levels are reduced in AKR-deficient strains [75]. Furthermore, renin-angiotensin system stimulates EPO secretion [76], and inhibition of GSH increases plasma renin activity [77].

\subsection{The assisting relationship between molecule groups and organs}

Moreover, as shown in Figure 1, we found that molecules of heart group assist spleen, spleen group assists lung, lung group assists kidney, kidney group assists liver, and liver group assists heart. Along the outer circle it follows the assisting sequence of heart-spleen-lungkidney-liver-heart. We have also found that the regulating sequence of heart-lung-liverspleen-kidney-heart, i.e., the diagonal direction. However, the inversed direction may have opposite effect.

\subsubsection{The assisting relationship of heart-spleen-lung-kidney-liver-heart}

The signaling molecules of heart group have assisting effect on spleen. For example, Mg deficiency causes morphological and immunological alterations in the spleen [78]; it was 
found that localized IGF-1 secretion enhances erythropoiesis in the spleen of murine embryos [79], lower IGF-I status is associated with higher spleen longitudinal diameter[80], and IGFI is necessary for survival or transition of myeloid progenitors into the spleen[81]; Ang II has a role in the establishment of an efficient $\mathrm{T}$ cell response in the spleen [82].

The signaling molecules of spleen group have assisting effect on lung. For example, ANP attenuates Lipopolysaccharides-induced lung vascular leak [83]; Retinoic acid regulates lung morphogenesis [84]; aldosterone may be used as a strategy to increase lung edema clearance [85]; and ghrelin is produced early by the fetal lung and promotes lung growth [86].

The signaling molecules of lung group have assisting effect on kidney. For example, HIF is involved in the regulation of a multitude of biological processes that are relevant to kidney function under physiological and pathological conditions, including glucose and energy metabolism, angiogenesis, erythropoiesis and iron homeostasis, cell migration, and cell-cell and cell-matrix interactions [87]; FGF-7 is part of the signaling pathway controlling collecting system size and nephron number in the kidney during development [88]; and VEGF is required for growth and proliferation of glomerular and peritubular endothelial cells [89].

The signaling molecules of kidney group have assisting effect on liver. For example, PTHrP activates human hepatic stellate cells[90] ; calcitonin intensificate the processes of conjugation of bile acids with amino acids taurine and glycine in hepatocytes and canalicular secretion that result in improvement of solubilization properties of the bile, ability of the bile to hold cholesterol in solute state and prevent the formation of calculi in biliary tracts [91]; short time lower dose of NO administration is good for liver, but long time high dose of NO administration is harmful for liver [92]; Wnt signaling contributes to liver physiology and pathology by regulating various basic cellular events, including differentiation, proliferation, survival, oxidative stress, and morphogenesis [93]. 
The signaling molecules of liver group have assisting effect on heart. For example, low GSH has high risk of cardiovascular disease [94]; treated with EPO, a significant improvement in cardiac function and symptoms can be found [95]; extracellular SOD protects the heart against oxidative stress and hypertrophy after myocardial infarction [96]; and AKR is activated in the ischemic heart [97].

\subsubsection{The regulating relationship of heart-lung-liver-spleen-kidney-heart}

The signaling molecules of heart group has regulating effect on lung. For example, IGF-1 induces lung fibroblast activation, and blockade of IGF pathway in murine model of lung fibrosis improved outcome and decreased fibrosis [98]; Ang II could mediate the response to lung injury [99]; and Mg deficiency contributes to pulmonary complications [100].

The signaling molecules of lung group has regulating effect on liver. It was found that FGF7 promotes liver regeneration [101]; VEGF promotes proliferation of hepatocytes through reconstruction of liver sinusoids by proliferation of sinusoidal endothelial cells [102]; vitamin C deficiency promotes fatty liver disease development [103] and vitamin C plus E combination treatment is a safe and effective treatment option in patients with fatty liver disease [104]; and HIF plays a role across a range of hepatic pathophysiology [105].

The signaling molecules of liver group has regulating effect on spleen, for example, EPO is necessary for the development of erythroid colonies in spleen [106].

The signaling molecules of spleen group has regulating effect on kidney, for example, ANP can act directly or indirectly (via inhibition of aldosterone biosynthesis) on the kidney to alter sodium transport and may regulate fluid distribution within the extracellular space [107]; Aldosterone is crucial for sodium conservation in the kidney [108]; retinoic acid is required for kidney development [109]; the kidney degrades ghrelin, and increased total 
ghrelin levels in chronic kidney disease are primarily due to the decreased degradation of ghrelin in the kidney [110].

The signaling molecules of kidney group also have regulating effect on heart organ. For example, NO regulates cardiac function through both vascular-dependent and independent effects [111]; congestive heart failure is associated with increased circulating calcitonin gene-related peptide (CGRP), but CGRP attenuates the development of myocardial infarction [112]; PTHrP has a protective effect for heart [113]; Wnt controls heart development but is also modulated during adult heart remodeling [114].

\subsection{The interrelationships among groups of molecules}

Figure 2 shows the pathways of the signaling molecules of the five groups. Along the outer circle heart-spleen-lung-kidney-liver-heart, the signaling molecules activate each other and form a clockwise closed-loop. As between liver group and heart group, EPO administration increases plasma IGF-I levels [115],

GSH enhances intracellular Mg both in vivo and in vitro [116]. Between heart group and spleen group, it was found that IGF-II increases the protein level of ANP [117], and Ang causes the release of aldosterone from the adrenal glands. Between spleen group and lung group, ghrelin administration significantly increased HIF-1 $\alpha$ and VEGF mRNAs [118], Aldosterone increases VEGF-A production in human neutrophils [119], and retinoic acid increases HIF-1 $\alpha$ [120] and markedly stimulates FGF7 expression [121]; however, ANP blocks VEGF production and signaling in vitro [122]. Between lung group and kidney group, HIF modulates Wnt/ $\beta$-catenin signaling [123], induces PTHrP [124], and is regulated by NO [125]; Wnt activates FGF7 during epidermal stratification [126], and regulates vitamin C biosynthesis [127]; and vitamin C increases nitric oxide synthase activity [128]. Between kidney group and liver group, calcitonin gene-related peptide (CGRP) and PTHrP stimulate 
renin secretion [129, 130], PTHrP and EPO are positively correlated with each other[131], PTHrP upregulates AKR 1C3[132], and NO stimulates EPO[133].

For the diagonal arrangement of heart-lung-liver-spleen-kidney-heart, the signaling molecules in each group also enhances those in following group. For example, between heart group and lung group, IGF-1 induces lung fibroblast activation [98] and induces VEGF [134]; and Ang II increases FGF7 mRNA levels [135] and stimulates VEGF synthesis [136]. Between lung group and liver group, VEGF is crucial for EPO-induced improvement of cardiac function [137]; vitamin C elevates red blood cell glutathione in healthy adults [138]; HIF induces EPO production [139] and induction of HIF-1 varies with the GSSG/GSH ratio [140]. Between liver group and spleen group, EPO stimulates ANP secretion [141], and ghrelin treatment increases GSH levels[142] and activity of SOD [143]. Between spleen group and kidney group, ANP increases calcitonin gene-related peptide (CGRP) within human circulation [144]. Between kidney group and heart group, calcitonin increases concentration of IGF [145], and IGF signaling antagonizes the Wnt pathway [146].

\section{Discussion}

Based on the five organs we categorize the signaling molecules into five groups, heart group, spleen group, lung group, kidney group and liver group, respectively. The assisting and regulating relationships follow the outer circle and diagonal arrangement in Figure 1. As shown in Figure 1, along the outer circle arrangement of heart-spleen-lung-kidney-liver-heart, the key molecule of each group is generated/secreted in the previous organ, for example, IGF in heart group is generated in liver, and so on. Within each group, the molecules are contrary but interdependent and regulate each other. Along the outer circle arrangement of heartspleen-lung-kidney-liver-heart, the molecules of each group have assisting effect on the corresponding organ and the following organ. For example, the molecules in heart group have assisting effect on heart and spleen, the molecules of spleen group have assisting effect 
on spleen and lung, the molecules in lung group have assisting effect on lung and kidney, the molecules in kidney group have assisting effect on kidney and liver, and the molecules of liver group have assisting effect on liver and heart. If in reversed order, then the key molecule of each group may have negative effect on the previous organ. For example, circulating ANP, the key molecule of spleen group, is greatly increased in congestive heart failure as a result of increased synthesis and release of this hormone [147]; VEGF, the key molecule of lung group, increases mobilization and recruitment of hematopoietic stem cells and circulating endothelial precursor cells to the spleen resulting in splenomegaly [148]; for the key molecules of kidney group, small cell carcinoma of lung is frequently associated with abnormally raised plasma calcitonin [149], and lung cancer is associated with high level of PTHrP [150]; for the key molecule of liver group, patients with polycystic kidney disease had higher levels of EPO [151]. However, IGF of heart group has positive effect on liver, for example the concentration of IGF-1 is low in patients with chronic liver disease mainly due to the decreased liver function [152].

Along the diagonal arrangement heart-lung-liver-spleen-kidney-heart, the molecules of each group also have positive/regulating effect on the following organ. For example, the molecules of heart group have positive effect on lung, the molecules of lung group have positive effect on liver, the molecules of liver group have positive effect on spleen, the molecules of spleen group have positive effect on kidney, and the molecules of kidney group have positive effect on heart. If in reversed order, the key molecule of each may have negative effect on the previous organ. For example, for the key molecule of heart group, higher serum IGF-1 levels were positively associated with chronic kidney disease [153]; for the key molecule of kidney group, calcitonin gene-related peptide suppresses spleen $\mathrm{T}$ lymphocyte proliferation [154] and endotoxin induces PTHrP gene expression in splenic stromal cells [155]; for the key molecule of liver group, the correlation between serum-EPO 
and lung function indices is negative, indicating a negative effect of EPO on lung function [156]. However, the key molecule of spleen group has positive effect on liver, as ANP protects liver from hypoxic injury [157]; and the key molecules of lung group also have positive effect on heart, for example VEGF and its receptors play a role in many different aspects of cardiovascular development, including stem cell differentiation into cardiomyocytes, stem cell migration and survival, and heart development [158], and treatment with VEGF and FGF7 can help to optimize the development of epicardium [159].

The pathways of the signaling molecules also follow the closed-loop arrangement of heart-spleen-lung-kidney-liver-heart. As shown in Figure 2, the molecules in heart group activate those in spleen group, the molecules in spleen group regulate those of lung group, the molecules of lung group regulate those of kidney group, the molecules of kidney group activate those of liver group, and the molecules of liver group regulate those of heart group.

Moreover, particularly the key molecule of each group follows the pathway of heartlung-liver-spleen-kidney-heart, the diagonal arrangement in Figure 2. The molecules of heart group activate those in lung group; the molecules of lung group activate the molecule in liver group; the key molecule of liver group activate the key molecule of spleen group, but ghrelin in spleen group activates GSH and SOD in liver group; the key molecule of spleen group activates the key molecule of kidney group; and the key molecule in kidney group activates the key molecule of heart group.

In conclusion, we categorized the signaling molecules into five groups according to their origin and effect on organs, and found the intrinsic relationships among these five group of molecules. These intrinsic relationships form the closed-loop of pathways of signaling molecules and follow the particular pathways. This enables us to investigate the effect of balance of signaling molecules on human health and understand the closed-loop of pathways 
bioRxiv preprint doi: https://doi.org/10.1101/129841; this version posted April 23, 2017. The copyright holder for this preprint (which was not certified by peer review) is the author/funder, who has granted bioRxiv a license to display the preprint in perpetuity. It is made available under ACC-BY-ND 4.0 International license.

of these molecules, that would lead to new therapeutic strategies and insight into the rules governing physiological processes. 
bioRxiv preprint doi: https://doi.org/10.1101/129841; this version posted April 23, 2017. The copyright holder for this preprint (which was not certified by peer review) is the author/funder, who has granted bioRxiv a license to display the preprint in perpetuity. It is made available under aCC-BY-ND 4.0 International license.

\section{References}

1. Troncoso, R., et al., New insights into IGF-1 signaling in the heart. Trends in Endocrinology and Metabolism, 2014. 25(3): p. 128-137.

2. Sanchez-Alavez, M., et al., Insulin-like Growth Factor 1-mediated Hyperthermia Involves Anterior Hypothalamic Insulin Receptors. Journal of Biological Chemistry, 2011. 286(17): p. 14983-14990.

3. De Mello, W.C. and A.H.J. Danser, Angiotensin II and the heart - On the intracrine renin-angiotensin system. Hypertension, 2000. 35(6): p. 1183-1188.

4. Wilson, K.M. and M.J. Fregly, Angiotensin Ii-Induced Hypothermia in Rats. Journal of Applied Physiology, 1985. 58(2): p. 534-543.

5. NIH-library-Mg. Magnesium. Available from: https://www.nlm.nih.gov/medlineplus/druginfo/natural/998.html.

6. Song, Y.H., et al., Muscle-specific expression of IGF-1 blocks angiotensin II-induced skeletal muscle wasting. Journal of Clinical Investigation, 2005. 115(2): p. 451-458.

7. Brink, M., et al., Angiotensin II stimulates gene expression of cardiac insulin-like growth factor I and its receptor through effects on blood pressure and food intake. Hypertension, 1999. 34(5): p. 10531059.

8. Ma, Y.W., et al., Angiotensin II stimulates transcription of insulin-like growth factor I receptor in vascular smooth muscle cells: Role of nuclear factor-kappa B. Endocrinology, 2006. 147(3): p. 12561263.

9. Kajstura, J., et al., IGF-1 overexpression inhibits the development of diabetic cardiomyopathy and angiotensin II-mediated oxidative stress. Diabetes, 2001. 50(6): p. 1414-1424.

10. Touyz, R.M. and E.L. Schiffrin, The effect of angiotensin II on platelet intracellular free magnesium and calcium ionic concentrations in essential hypertension. J Hypertens, 1993. 11(5): p. 551-8.

11. Maggio, M., et al., Magnesium and anabolic hormones in older men. International Journal of Andrology, 2011. 34(6): p. E594-E600.

12. Debold, A.J., Atrial Natriuretic Factor - a Hormone Produced by the Heart. Science, 1985. 230(4727): p. 767-770.

13. Sultanian, R., Y.M. Deng, and S. Kaufman, Atrial natriuretic factor increases splenic microvascular pressure and fluid extravasation in the rat. Journal of Physiology-London, 2001. 533(1): p. 273-280.

14. Palmer, B.F. and D.J. Clegg, An Emerging Role of Natriuretic Peptides: Igniting the Fat Furnace to Fuel and Warm the Heart. Mayo Clinic Proceedings, 2015. 90(12): p. 1666-1678.

15. Delcayre, C., et al., Cardiac aldosterone production and ventricular remodeling. Kidney International, 2000. 57(4): p. 1346-1351.

16. McGraw, A.P., et al., Aldosterone Increases Early Atherosclerosis and Promotes Plaque Inflammation Through a Placental Growth Factor-Dependent Mechanism. Journal of the American Heart Association, 2013. 2(1).

17. Klebanoff, C.A., et al., Retinoic acid controls the homeostasis of pre-cDC-derived splenic and intestinal dendritic cells. Journal of Experimental Medicine, 2013. 210(10): p. 1961-1976.

18. Chen, T.H.P., et al., Epicardial induction of fetal cardiomyocyte proliferation via a retinoic acidinducible trophic factor. Developmental Biology, 2002. 250(1): p. 198-207.

19. Marzolla, V., et al., The role of the mineralocorticoid receptor in adipocyte biology and fat metabolism. Molecular and Cellular Endocrinology, 2012. 350(2): p. 281-288.

20. Murholm, M., et al., Retinoic acid has different effects on UCP1 expression in mouse and human adipocytes. Bmc Cell Biology, 2013. 14.

21. Xia, Q., et al., Effects of ghrelin on the proliferation and secretion of splenic T lymphocytes in mice. Regulatory Peptides, 2004. 122(3): p. 173-178.

22. Ueno, H., et al., Ghrelin: a gastric peptide that regulates food intake and energy homeostasis. Regulatory Peptides, 2005. 126(1-2): p. 11-19.

23. Klabunde, R.E., Cardiovascular physiology concepts. 2nd ed. 2012, Philadelphia: Wolters Kluwer Health/Lippincott Williams \& Wilkins. xi, 243 p.

24. Kumar, P., et al., All-Trans Retinoic Acid and Sodium Butyrate Enhance Natriuretic Peptide Receptor A Gene Transcription: Role of Histone Modification. Molecular Pharmacology, 2014. 85(6): p. 946957.

25. Torsello, A., et al., Ghrelin plays a minor role in the physiological control of cardiac function in the rat. Endocrinology, 2003. 144(5): p. 1787-1792.

26. Milosevic, V.L., et al., Central effects of ghrelin on the adrenal cortex: a morphological and hormonal study. General Physiology and Biophysics, 2010. 29(2): p. 194-202.

27. Pereira-Terra, P., et al., Neuroendocrine factors regulate retinoic acid receptors in normal and hypoplastic lung development. Journal of Physiology-London, 2015. 593(15): p. 3301-3311. 
bioRxiv preprint doi: https://doi.org/10.1101/129841; this version posted April 23, 2017. The copyright holder for this preprint (which was not certified by peer review) is the author/funder, who has granted bioRxiv a license to display the preprint in perpetuity. It is made available under aCC-BY-ND 4.0 International license.

28. Suzuki, M., et al., Spleen-Derived Growth-Factor, Sdgf-3, Is Identified as Keratinocyte Growth-Factor $($ Kgf). Febs Letters, 1993. 328(1-2): p. 17-20.

29. Tichelaar, J.W., W. Lu, and J.A. Whitsett, Conditional expression of fibroblast growth factor-7 in the developing and mature lung. J Biol Chem, 2000. 275(16): p. 11858-64.

30. Voelkel, N.F., R.W. Vandivier, and R.M. Tuder, Vascular endothelial growth factor in the lung. American Journal of Physiology-Lung Cellular and Molecular Physiology, 2006. 290(2): p. L209L221.

31. Owen, J.L., et al., Up-regulation of matrix metalloproteinase-9 in T lymphocytes of mammary tumor bearers: role of vascular endothelial growth factor. J Immunol, 2003. 171(8): p. 4340-51.

32. Bagchi, M., et al., Vascular endothelial growth factor is important for brown adipose tissue development and maintenance. Faseb Journal, 2013. 27(8): p. 3257-3271.

33. Hemila, H. and P. Louhiala, Vitamin C may affect lung infections. Journal of the Royal Society of Medicine, 2007. 100(11): p. 495-498.

34. Fisher, B.J., et al., Ascorbic acid attenuates lipopolysaccharide-induced acute lung injury. Critical Care Medicine, 2011. 39(6): p. 1454-1460.

35. Tsao, C.S., P.Y. Leung, and M. Young, Effect of Dietary Ascorbic-Acid Intake on Tissue Vitamin-C in Mice. Journal of Nutrition, 1987. 117(2): p. 291-297.

36. Willis, R.J. and C.C. Kratzing, Extracellular Ascorbic-Acid in Lung. Biochimica Et Biophysica Acta, 1976. 444(1): p. 108-117.

37. Shimoda, L.A. and G.L. Semenza, HIF and the Lung Role of Hypoxia-inducible Factors in Pulmonary Development and Disease. American Journal of Respiratory and Critical Care Medicine, 2011. 183(2): p. 152-156.

38. Forsythe, J.A., et al., Activation of vascular endothelial growth factor gene transcription by hypoxiainducible factor 1. Molecular and Cellular Biology, 1996. 16(9): p. 4604-4613.

39. Tsuji, K., S. Kitamura, and H. Makino, Hypoxia-inducible factor 1 alpha regulates branching morphogenesis during kidney development. Biochemical and Biophysical Research Communications, 2014. 447(1): p. 108-114.

40. Rodriguez, J.A., et al., Vitamins $C$ and E prevent endothelial VEGF and VEGFR-2 overexpression induced by porcine hypercholesterolemic LDL. Cardiovascular Research, 2005. 65(3): p. 665-673.

41. Muellner, M.K., et al., Vitamin C inhibits NO-induced stabilization of HIF-1 alpha in HUVECs. Free Radical Research, 2010. 44(7): p. 783-791.

42. Gomez-Roman, J.J., et al., Hormone expression and opioid receptors in fetal and adult lung. Archivos De Bronconeumologia, 2002. 38(8): p. 362-366.

43. Hastings, R.H., et al., Alveolar Epithelial-Cells Express and Secrete Parathyroid Hormone-Related Protein. American Journal of Respiratory Cell and Molecular Biology, 1994. 11(6): p. 701-706.

44. Hsu, Y.J., et al., Calcitonin-stimulated renal Ca2+ reabsorption occurs independently of TRPV5. Nephrology Dialysis Transplantation, 2010. 25(5): p. 1428-1435.

45. Esbrit, P. and J. Egido, The emerging role of parathyroid hormone-related protein as a renal regulating factor. Nephrology Dialysis Transplantation, 2000. 15(8): p. 1109-1111.

46. Fargeas, M.J., J. Fioramonti, and L. Bueno, Central Actions of Calcitonin on Body-Temperature and Intestinal Motility in Rats - Evidence for Different Mediations. Regulatory Peptides, 1985. 11(2): p. 95103.

47. Kir, S., et al., Tumour-derived PTH-related protein triggers adipose tissue browning and cancer cachexia. Nature, 2014. 513(7516): p. 100-+.

48. Pulkkinen, K., S. Murugan, and S. Vainio, Wnt signaling in kidney development and disease. Organogenesis, 2008. 4(2): p. 55-9.

49. Dean, C.H., et al., Canonical Wnt signaling negatively regulates branching morphogenesis of the lung and lacrimal gland. Developmental Biology, 2005. 286(1): p. 270-286.

50. Kang, S., et al., Effects of wnt signaling on brown adipocyte differentiation and metabolism mediated by PGC-1 alpha. Molecular and Cellular Biology, 2005. 25(4): p. 1272-1282.

51. Mount, P.F. and D.A. Power, Nitric oxide in the kidney: functions and regulation of synthesis. Acta Physiol (Oxf), 2006. 187(4): p. 433-46.

52. Gooi, J.H., et al., Calcitonin impairs the anabolic effect of PTH in young rats and stimulates expression of sclerostin by osteocytes. Bone, 2010. 46(6): p. 1486-1497.

53. Lopez-Herradon, A., et al., Inhibition of the canonical Wnt pathway by high glucose can be reversed by parathyroid hormone-related protein in osteoblastic cells. Journal of Cellular Biochemistry, 2013. 114(8): p. 1908-1916.

54. Tas, N., et al., The effect of calcitonin treatment on plasma nitric oxide levels in post-menopausal osteoporotic patients. Cell Biochemistry and Function, 2002. 20(2): p. 103-105. 
bioRxiv preprint doi: https://doi.org/10.1101/129841; this version posted April 23, 2017. The copyright holder for this preprint (which was not certified by peer review) is the author/funder, who has granted bioRxiv a license to display the preprint in perpetuity. It is made available under aCC-BY-ND 4.0 International license.

55. Kalinowski, L., L.W. Dobrucki, and T. Malinski, Nitric oxide as a second messenger in parathyroid hormone-related protein signaling. Journal of Endocrinology, 2001. 170(2): p. 433-440.

56. Munoz, F.J., et al., Wnt-5 alpha increases NO and modulates NMDA receptor in rat hippocampal neurons. Biochemical and Biophysical Research Communications, 2014. 444(2): p. 189-194.

57. Zanjani, E.D., et al., Studies on the liver to kidney switch of erythropoietin production. J Clin Invest, 1981. 67(4): p. 1183-8.

58. Gul, M., et al., Effect of erythropoietin on liver regeneration in an experimental model of partial hepatectomy. International Journal of Surgery, 2013. 11(1): p. 59-63.

59. Wang, L., et al., PPAR alpha and Sirt1 Mediate Erythropoietin Action in Increasing Metabolic Activity and Browning of White Adipocytes to Protect Against Obesity and Metabolic Disorders. Diabetes, 2013. 62(12): p. 4122-4131.

60. Ayers, C.R., Plasma Renin Activity and Renin-Substrate Concentration in Patients with Liver Disease. Circulation Research, 1967. 20(6): p. 594-\&.

61. Koh, S.L., et al., Blockade of the renin-angiotensin system improves the early stages of liver regeneration and liver function. Journal of Surgical Research, 2013. 179(1): p. 66-71.

62. Suh, J.G., et al., Sequence analysis, tissue expression and chromosomal localization of a mouse secreted superoxide dismutase gene. Molecules and Cells, 1997. 7(2): p. 204-207.

63. Cui, Y.Y., et al., SOD Mimetic Improves the Function, Growth, and Survival of Small-Size Liver Grafts After Transplantation in Rats. Transplantation, 2012. 94(7): p. 687-694.

64. Okado-Matsumoto, A. and I. Fridovich, Subcellular distribution of superoxide dismutases (SOD) in rat liver: $\mathrm{Cu}, \mathrm{Zn}$-SOD in mitochondria. J Biol Chem, 2001. 276(42): p. 38388-93.

65. Petrovic, V., et al., Antioxidative defense and mitochondrial thermogenic response in brown adipose tissue. Genes and Nutrition, 2010. 5(3): p. 225-235.

66. MacLeod, A.K., et al., Expression and Localization of Rat Aldo-Keto Reductases and Induction of the $1 B 13$ and 1D2 Isoforms by Phenolic Antioxidants. Drug Metabolism and Disposition, 2010. 38(2): p. 341-346.

67. Barski, O.A., S.M. Tipparaju, and A. Bhatnagar, The Aldo-Keto Reductase Superfamily and Its Role in Drug Metabolism and Detoxification. Drug Metabolism Reviews, 2008. 40(4): p. 553-624.

68. Ahmed, M.M.E., et al., Aldo-Keto Reductase-7A Protects Liver Cells and Tissues From Acetaminophen-Induced Oxidative Stress and Hepatotoxicity. Hepatology, 2011. 54(4): p. 1322-1332.

69. Shore, A.M., et al., Cold-Induced Changes in Gene Expression in Brown Adipose Tissue, White Adipose Tissue and Liver. Plos One, 2013. 8(7).

70. Wu, G.Y., et al., Glutathione metabolism and its implications for health. Journal of Nutrition, 2004. 134(3): p. 489-492.

71. Hussein, A.M., et al., Effects of combined erythropoietin and epidermal growth factor on renal ischaemia/reperfusion injury: a randomized experimental controlled study. Bju International, 2011. 107(2): p. 323-328.

72. Zelko, I.N. and R.J. Folz, Extracellular superoxide dismutase functions as a major repressor of hypoxia-induced erythropoietin gene expression. Endocrinology, 2005. 146(1): p. 332-340.

73. d'Uscio, L.V., L.A. Smith, and Z.S. Katusic, Erythropoietin Increases Expression and Function of Vascular Copper- and Zinc-Containing Superoxide Dismutase. Hypertension, 2010. 55(4): p. 9981004.

74. Weydert, C.J. and J.J. Cullen, Measurement of superoxide dismutase, catalase and glutathione peroxidase in cultured cells and tissue. Nature Protocols, 2010. 5(1): p. 51-66.

75. Chang, Q. and J.M. Petrash, Disruption of aldo-keto reductase genes leads to elevated markers of oxidative stress and inositol auxotrophy in Saccharomyces cerevisiae. Biochimica Et Biophysica ActaMolecular Cell Research, 2008. 1783(2): p. 237-245.

76. Vlahakos, D.V., et al., Renin-Angiotensin System Stimulates Erythropoietin Secretion in ChronicHemodialysis Patients. Clinical Nephrology, 1995. 43(1): p. 53-59.

77. Murakami, E., et al., Blood-Pressure Elevation Caused by Inhibition of Brain Glutathione-Reductase. Journal of Hypertension, Vol 7, Suppl 6, 1989: p. S24-S25.

78. Malpuech-Brugere, C., et al., Early morphological and immunological alterations in the spleen during magnesium deficiency in the rat. Magnesium research, 1998. 11(3): p. 161-169.

79. Tan, K.S., et al., Localized SCF and IGF-1 secretion enhances erythropoiesis in the spleen of murine embryos. Biology open, 2015. 4(5): p. 596-607.

80. Savastano, S., et al., Liver-spleen axis, insulin-like growth factor-(IGF)-I axis and fat mass in overweight/obese females. Journal of translational medicine, 2011. 9(1): p. 136.

81. Welniak, L.A., et al., Effects of organ-specific loss of insulin-like growth factor-I production on murine hematopoiesis. Biology of Blood and Marrow Transplantation, 2004. 10(1): p. 32-39. 
bioRxiv preprint doi: https://doi.org/10.1101/129841; this version posted April 23, 2017. The copyright holder for this preprint (which was not certified by peer review) is the author/funder, who has granted bioRxiv a license to display the preprint in perpetuity. It is made available under aCC-BY-ND 4.0 International license.

82. Silva-Filho, J.L., et al., Angiotensin II is a new component involved in splenic T lymphocyte responses during Plasmodium berghei ANKA infection. PloS one, 2013. 8(4): p. e62999.

83. Birukova, A.A., et al., Atrial natriuretic peptide attenuates LPS-induced lung vascular leak: role of PAK1. American Journal of Physiology-Lung Cellular and Molecular Physiology, 2010. 299(5): p. L652-L663.

84. Malpel, S., C. Mendelsohn, and W.V. Cardoso, Regulation of retinoic acid signaling during lung morphogenesis. DEVELOPMENT-CAMBRIDGE-, 2000. 127(14): p. 3057-3067.

85. Olivera, W.G., et al., Aldosterone regulates $\mathrm{Na}$, K-ATPase and increases lung edema clearance in rats. American journal of respiratory and critical care medicine, 2000. 161(2): p. 567-573.

86. Santos, M., et al., Ghrelin expression in human and rat fetal lungs and the effect of ghrelin administration in nitrofen-induced congenital diaphragmatic hernia. Pediatric research, 2006. 59: p. 531-537.

87. Haase, V.H., Hypoxia-inducible factors in the kidney. American Journal of Physiology-Renal Physiology, 2006. 291(2): p. F271-F281.

88. Qiao, J., et al., FGF-7 modulates ureteric bud growth and nephron number in the developing kidney. Development, 1999. 126(3): p. 547-554.

89. Schrijvers, B.F., A. Flyvbjerg, and A.S. De Vriese, The role of vascular endothelial growth factor (VEGF) in renal pathophysiology. Kidney international, 2004. 65(6): p. 2003-2017.

90. Liang, F.-F., et al., Activated effects of parathyroid hormone-related protein on human hepatic stellate cells. PloS one, 2013. 8(10): p. e76517.

91. Gorenko, Z.A., et al., The Influence of Calcitonin on the Liver Bile Formation Function in Rats. International Journal of Physiology and Pathophysiology, 2012. 3(1).

92. Hon, W.M., K.H. Lee, and H.E. Khoo, Nitric oxide in liver diseases. Annals of the New York Academy of Sciences, 2002. 962(1): p. 275-295.

93. Thompson, M.D. and S.P. Monga, WNT/ $\beta$-catenin signaling in liver health and disease. Hepatology, 2007. 45(5): p. 1298-1305.

94. Shimizu, H., et al., Relationship between plasma glutathione levels and cardiovascular disease in a defined population. Stroke, 2004. 35(9): p. 2072-2077.

95. van der Meer, P., et al., Erythropoietin in cardiovascular diseases. European Heart Journal, 2004. 25(4): p. 285-291.

96. van Deel, E.D., et al., Extracellular superoxide dismutase protects the heart against oxidative stress and hypertrophy after myocardial infarction. Free Radical Biology and Medicine, 2008. 44(7): p. 1305-1313.

97. Kaiserova, K., et al., Redox activation of aldose reductase in the ischemic heart. Journal of Biological Chemistry, 2006. 281(22): p. 15110-15120.

98. Hung, C.F., et al., Role of IGF-1 pathway in lung fibroblast activation. Respiratory Research, 2013.14.

99. Marshall, R.P., The pulmonary renin-angiotensin system. Current pharmaceutical design, 2003. 9(9): p. 715-722.

100. Landon, R.A. and E.A. Young, Role of magnesium in regulation of lung function. J Am Diet Assoc, 1993. 93(6): p. 674-7.

101. Takase, H.M., et al., FGF7 is a functional niche signal required for stimulation of adult liver progenitor cells that support liver regeneration. Genes \& Development, 2013. 27(2): p. 169-181.

102. Taniguchi, E., et al., Expression and role of vascular endothelial growth factor in liver regeneration after partial hepatectomy in rats. Journal of Histochemistry \& Cytochemistry, 2001. 49(1): p. 121-129.

103. Ipsen, D.H., P. Tveden-Nyborg, and J. Lykkesfeldt, Does Vitamin C Deficiency Promote Fatty Liver Disease Development? Nutrients, 2014. 6(12): p. 5473-5499.

104. Ersoz, G., et al., Management of fatty liver disease with vitamin $E$ and $C$ compared to ursodeoxycholic acid treatment. Turk J Gastroenterol, 2005. 16(3): p. 124-8.

105. Nath, B. and G. Szabo, Hypoxia and hypoxia inducible factors: Diverse roles in liver diseases. Hepatology, 2012. 55(2): p. 622-633.

106. Schooley, J.C., The effect of erythropoietin on the growth and development of spleen colony-forming cells. Journal of Cellular Physiology, 1966. 68(3): p. 249-262.

107. Blaine, E.H., Atrial natriuretic factor plays a significant role in body fluid homeostasis. Hypertension, 1990. 15(1): p. 2-8.

108. Arai, K. and G.P. Chrousos, Aldosterone deficiency and resistance. 2016.

109. Mallipattu, S.K. and J.C. He, The beneficial role of retinoids in glomerular disease. Frontiers in medicine, 2015. 2.

110. Yoshimoto, A., et al., Plasma ghrelin and desacyl ghrelin concentrations in renal failure. Journal of the American Society of Nephrology, 2002. 13(11): p. 2748-2752.

111. Massion, P., et al., Nitric oxide and cardiac function. Circulation research, 2003. 93(5): p. 388-398. 
bioRxiv preprint doi: https://doi.org/10.1101/129841; this version posted April 23, 2017. The copyright holder for this preprint (which was not certified by peer review) is the author/funder, who has granted bioRxiv a license to display the preprint in perpetuity. It is made available under aCC-BY-ND 4.0 International license.

112. Franco-Cereceda, A. and J. Liska, Potential of calcitonin gene-related peptide in coronary heart disease. Pharmacology, 2000. 60(1): p. 1-8.

113. Ross, G. and K.-D. Schlüter, Cardiac-specific effects of parathyroid hormone-related peptide: Modification by aging and hypertension. Cardiovascular research, 2005. 66(2): p. 334-344.

114. Bergmann, M.W., WNT signaling in adult cardiac hypertrophy and remodeling. Circulation research, 2010. 107(10): p. 1198-1208.

115. Sohmiya, M. and Y. Sohmiya, Effects of Recombinant Human Erythropoietin (rHuEPO) Treatment on Plasma Insulin-like Growth Factor-I (IGF-I) and Hemoglobin Concentra-tions in Patients with Type 2 Diabetes Mellitus Associated with Neph-ropathy and Anemia of Chronic Renal Failure. Biomedical Research, 2010. 21(1).

116. Barbagallo, M., et al., Effects of glutathione on red blood cell intracellular magnesium - Relation to glucose metabolism. Hypertension, 1999. 34(1): p. 76-82.

117. Chu, C.H., et al., IGF-II/mannose-6-phosphate receptor signaling induced cell hypertrophy and atrial natriuretic peptide/BNP expression via $G$ alpha $q$ interaction and protein kinase $C$-alpha/CaMKII activation in H9c2 cardiomyoblast cells. Journal of Endocrinology, 2008. 197(2): p. 381-390.

118. Konturek, P.C., et al., Ghrelin-induced gastroprotection against ischemia-reperfusion injury involves an activation of sensory afferent nerves and hyperemia mediated by nitric oxide. European Journal of Pharmacology, 2006. 536(1-2): p. 171-181.

119. Walczak, C., et al., Aldosterone increases VEGF-A production in human neutrophils through PI3K, ERK1/2 and p38 pathways. Biochimica et Biophysica Acta (BBA)-Molecular Cell Research, 2011. 1813(12): p. 2125-2132.

120. Fernandez-Martinez, A.B., M.I.A. Jimenez, and F.J.L. Cazana, Retinoic acid increases hypoxiainducible factor-1 alpha through intracrine prostaglandin E-2 signaling in human renal proximal tubular cells HK-2. Biochimica Et Biophysica Acta-Molecular and Cell Biology of Lipids, 2012. 1821(4): p. 672-683.

121. Mackenzie, I.C. and Z.R. Gao, Keratinocyte growth factor expression in human gingival fibroblasts and stimulation of in vitro gene expression by retinoic acid. Journal of Periodontology, 2001. 72(4): p. 445-453.

122. Lara-Castillo, N., et al., Atrial natriuretic peptide reduces vascular leakage and choroidal neovascularization. The American journal of pathology, 2009. 175(6): p. 2343-2350.

123. Mazumdar, J., et al., O-2 regulates stem cells through Wnt/beta-catenin signalling. Nature Cell Biology, 2010. 12(10): p. 1007-1013.

124. Pelosi, M., et al., Parathyroid hormone-related protein is induced by hypoxia and promotes expression of the differentiated phenotype of human articular chondrocytes. Clinical Science, 2013. 125(9-10): p. 461-470.

125. Agani, F.H., et al., Role of nitric oxide in the regulation of HIF-1 alpha expression during hypoxia. American Journal of Physiology-Cell Physiology, 2002. 283(1): p. C178-C186.

126. Zhu, X.J., et al., BMP-FGF signaling axis mediates Wnt-induced epidermal stratification in developing mammalian skin. PLoS Genet, 2014. 10(10): p. e1004687.

127. Nejak-Bowen, K.N., et al., beta-Catenin Regulates Vitamin C Biosynthesis and Cell Survival in Murine Liver. Journal of Biological Chemistry, 2009. 284(41): p. 28115-28127.

128. d'Uscio, L.V., et al., Long-term vitamin C treatment increases vascular tetrahydrobiopterin levels and nitric oxide synthase activity. Circulation Research, 2003. 92(1): p. 88-95.

129. Kurtz, A., et al., Calcitonin gene-related peptide is a stimulator of renin secretion. Journal of Clinical Investigation, 1988. 82(2): p. 538.

130. Atchison, D.K., et al., Parathyroid hormone-related protein stimulates plasma renin activity via its anorexic effects on sodium chloride intake. American Journal of Physiology-Endocrinology and Metabolism, 2012. 303(4): p. E457-E463.

131. Feng, C.-c., et al., Paraneoplastic hormones: parathyroid hormone-related protein (PTHrP) and erythropoietin (EPO) are related to vascular endothelial growth factor (VEGF) expression in clear cell renal cell carcinoma. Tumor Biology, 2013. 34(6): p. 3471-3476.

132. Downs, T.M., et al., PTHrP stimulates prostate cancer cell growth and upregulates aldo-keto reductase 1C3. Cancer letters, 2011. 306(1): p. 52-59.

133. Cokic, B.B.B., et al., Nitric oxide and hypoxia stimulate erythropoietin receptor via MAPK kinase in endothelial cells. Microvascular research, 2014. 92: p. 34-40.

134. Slomiany, M.G. and S.A. Rosenzweig, IGF-1-induced VEGF and IGFBP-3 secretion correlates with increased HIF-1 alpha expression and activity in retinal pigment epithelial cell line D407.

Investigative Ophthalmology \& Visual Science, 2004. 45(8): p. 2838-2847. 
bioRxiv preprint doi: https://doi.org/10.1101/129841; this version posted April 23, 2017. The copyright holder for this preprint (which was not certified by peer review) is the author/funder, who has granted bioRxiv a license to display the preprint in perpetuity. It is made available under aCC-BY-ND 4.0 International license.

135. Stirling, D., et al., Angiotensin-Ii Inhibits Luteinizing Hormone-Stimulated Cholesterol Side-Chain Cleavage Expression and Stimulates Basic Fibroblast Growth-Factor Expression in Bovine Luteal Cells in Primary Culture. Journal of Biological Chemistry, 1990. 265(1): p. 5-8.

136. Pupilli, C., et al., Angiotensin II stimulates the synthesis and secretion of vascular permeability factor vascular endothelial growth factor in human mesangial cells. Journal of the American Society of Nephrology, 1999. 10(2): p. 245-255.

137. Westenbrink, B.D., et al., Vascular endothelial growth factor is crucial for erythropoietin-induced improvement of cardiac function in heart failure. Cardiovascular Research, 2010. 87(1): p. 30-39.

138. Johnston, C.S., C.G. Meyer, and J.C. Srilakshmi, Vitamin-C Elevates Red-Blood-Cell Glutathione in Healthy-Adults. American Journal of Clinical Nutrition, 1993. 58(1): p. 103-105.

139. Wang, G.L., et al., Hypoxia-Inducible Factor-1 Is a Basic-Helix-Loop-Helix-Pas Heterodimer Regulated by Cellular O-2 Tension. Proceedings of the National Academy of Sciences of the United States of America, 1995. 92(12): p. 5510-5514.

140. Tajima, M., et al., The redox state of glutathione regulates the hypoxic induction of HIF-1. European Journal of Pharmacology, 2009. 606(1-3): p. 45-49.

141. Porat, O., et al., Erythropoietin stimulates atrial natriuretic peptide secretion from adult rat cardiac atrium. J Pharmacol Exp Ther, 1996. 276(3): p. 1162-8.

142. Cao, Y.K., et al., Cardioprotective Effect of Ghrelin in Cardiopulmonary Bypass Involves a Reduction in Inflammatory Response. Plos One, 2013. 8(1).

143. Zwirska-Korczala, K., et al., Role of leptin, ghrelin, angiotensin II and orexins in $3 T 3$ L1 preadipocyte cells proliferation and oxidative metabolism. J Physiol Pharmacol, 2007. 58 Suppl 1: p. 53-64.

144. Vesely, D.L., et al., Atrial natriuretic peptides increase calcitonin gene-related peptide within human circulation. Metabolism-Clinical and Experimental, 1997. 46(7): p. 818-825.

145. Farley, J., et al., Calcitonin increases the concentration of insulin-like growth factors in serum-free cultures of human osteoblast-line cells. Calcified Tissue International, 2000. 67(3): p. 247-254.

146. Schlupf, J. and H. Steinbeisser, IGF antagonizes the Wnt/beta-Catenin pathway and promotes differentiation of extra-embryonic endoderm. Differentiation, 2014. 87(5): p. 209-219.

147. Brandt, R.R., et al., Atrial natriuretic peptide in heart failure. Journal of the American College of Cardiology, 1993. 22(4): p. A86-A92.

148. Hattori, K., et al., Vascular endothelial growth factor and angiopoietin-1 stimulate postnatal hematopoiesis by recruitment of vasculogenic and hematopoietic stem cells. The Journal of experimental medicine, 2001. 193(9): p. 1005-1014.

149. Gropp, C., K. Havemann, and A. Scheuer, Ectopic hormones in lung cancer patients at diagnosis and during therapy. Cancer, 1980. 46(2): p. 347-354.

150. Furlhata, M., et al., Lung squamous cell carcinoma producing both parathyroid hormone-related peptide and granulocyte colony stimulating factor. Pathology international, 1996. 46(5): p. 376-379.

151. Chandra, M., et al., Serum immunoreactive erythropoietin levels in patients with polycystic kidney disease as compared with other hemodialysis patients. Nephron, 1985. 39(1): p. 26-29.

152. Møller, S. and U. Becker, Insulin-like growth factor 1 and growth hormone in chronic liver disease. Digestive diseases, 1992. 10(4): p. 239-248.

153. Teppala, S., A. Shankar, and C. Sabanayagam, Association between IGF-1 and chronic kidney disease among US adults. Clinical and experimental nephrology, 2010. 14(5): p. 440-444.

154. Haberstock-Debic, H., et al., Calcitonin gene-related peptide receptors in pig spleen and the involvement of the CGRP 1 receptor in the splenocyte function. Neuropeptides, 1999. 33(1): p. 47-53.

155. Funk, J.L., et al., Endotoxin induces parathyroid hormone-related protein gene expression in splenic stromal and smooth muscle cells, not in splenic lymphocytes. Endocrinology, 1995. 136(8): p. 34123421.

156. Graudal, N., A. Galløe, and O. Nielsen, Erythropoietin in chronic obstructive pulmonary disease. Respiration, 1991. 58(3-4): p. 141-144.

157. Carini, R., et al., Mechanisms of hepatocyte protection against hypoxic injury by atrial natriuretic peptide. Hepatology, 2003. 37(2): p. 277-285.

158. Madonna, R. and R. De Caterina, VEGF receptor switching in heart development and disease. Cardiovascular research 2009. 84(1): p. 4-6.

159. Smart, N., et al., Thymosin $\beta 4$ induces adult epicardial progenitor mobilization and neovascularization. Nature, 2007. 445(7124): p. 177-182. 
Table 1 Groups of signaling molecules

\begin{tabular}{lccc} 
& $\phi 1$ & $\phi 2$ & $\phi 3$ \\
\hline Heart Group & IGF & Ang & Mg \\
\hline Spleen Group & ANP & $\begin{array}{l}\text { aldosterone, } \\
\text { retinoic acid }\end{array}$ & ghrelin \\
\hline Lung Group & FGF7, VEGF & ascorbic acid & HIF \\
\hline Kidney Group & calcitonin, PTHrP & Wnt & NO \\
\hline Liver Group & EPO, HGF & renin, SOD, AKR & GSH \\
\hline
\end{tabular}




\section{Figure Legends}

Figure 1. The interrelationships of five group of signaling molecules with organs. The small square indicates the closed-loop pathways of signaling molecules within the same group. Along the outer circle, the thick red arrow shows that the group of molecules assists the following organ, and it follows heart-spleen-lung-kidney-liver-heart arrangement. In the diagonal direction, the thick green arrow shows that the group of molecules assists the following organ, and it follows heart-lung-liver-spleen-kidneyheart arrangement. Arrow means assisting/increasing, solid circle means inhibiting/decreasing, and arrow and circle together indicate regulating.

Figure 2. The pathways of signaling molecules among the five groups of molecules. Along the outer circle, the pathways follow the order of heart-spleen-lung-kidney-liver-heart groups. In the diagonal arrangement, the pathways follow the order of heart-lungliver-spleen-kidney-heart groups. Arrow means increasing, solid circle means decreasing, and arrow and circle together indicate regulating. 


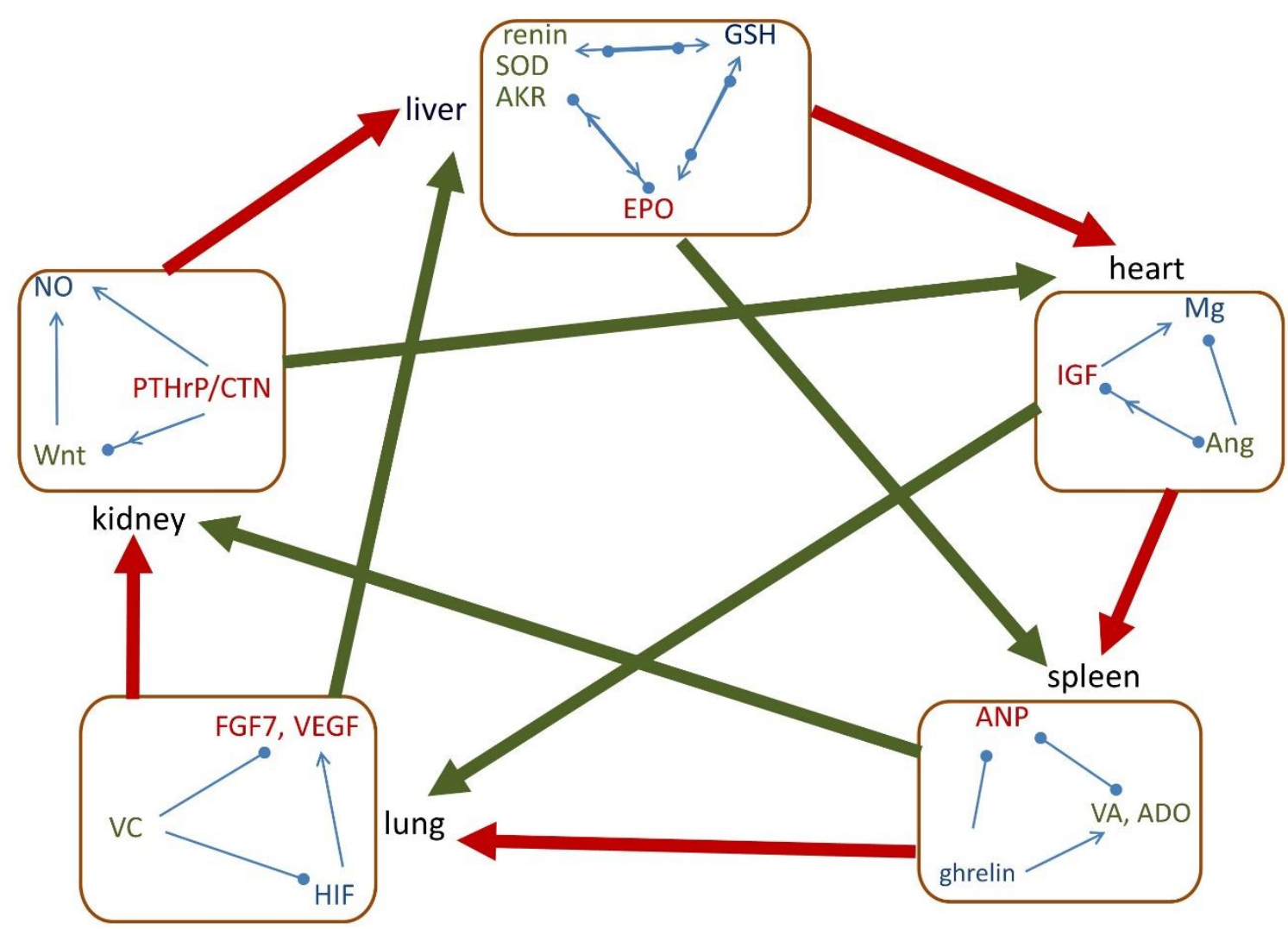

Figure 1. The interrelationships of five group of signaling molecules with organs. The small square indicates the closed-loop pathways of signaling molecules within the same group. Along the outer circle, the thick red arrow shows that the group of molecules assists the following organ, and it follows heart-spleen-lung-kidney-liver-heart arrangement. In the diagonal direction, the thick green arrow shows that the group of molecules assists the following organ, and it follows heart-lung-liver-spleen-kidneyheart arrangement. Arrow means assisting/increasing, solid circle means inhibiting/decreasing, and arrow and circle together indicate regulating. 


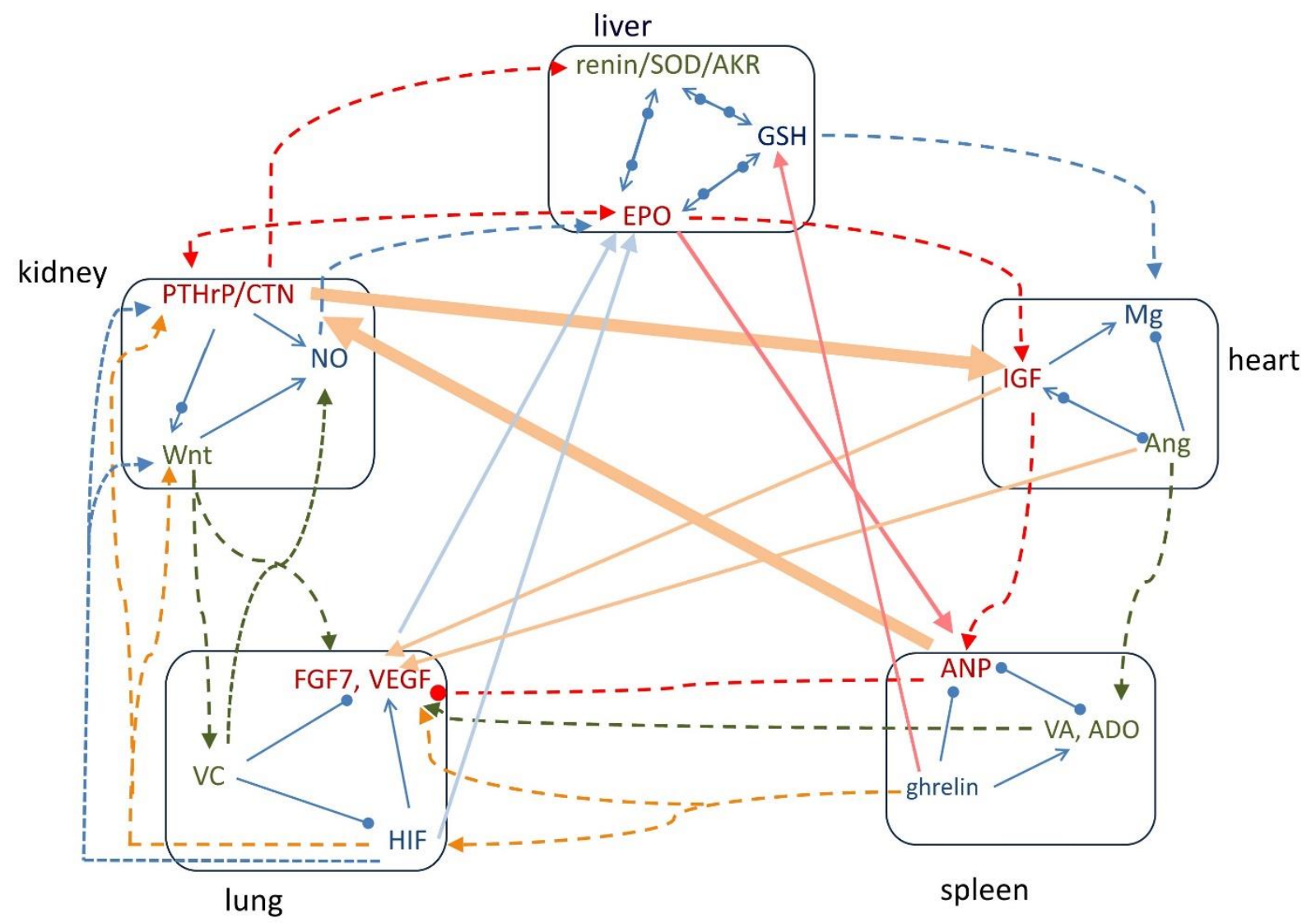

Figure 2. The pathways of signaling molecules among the five groups of molecules. Along the outer circle, the pathways follow the order of heart-spleen-lung-kidney-liver-heart groups. In the diagonal arrangement, the pathways follow the order of heart-lungliver-spleen-kidney-heart groups. Arrow means increasing, solid circle means decreasing, and arrow and circle together indicate regulating. 